\title{
Functional impairment as a proxy measure indicating high rates of trauma exposure, post-migration living difficulties, common mental disorders, and poor health amongst Rohingya refugees in Malaysia
}

\author{
Alvin Kuowei Tay', Susan Rees', Mohammed Abdul Awal Miah', Sanjida Khan², Mohammad Badrudduza', \\ Karen Morgan ${ }^{3}$, Darlina Fadil Azim ${ }^{3}$, Susheela Balasundaram ${ }^{4}$ and Derrick Silove ${ }^{1}$
}

\begin{abstract}
A major challenge in the refugee field is to ensure that scarce mental health resources are directed to those in greatest need. Based on data from an epidemiological survey of 959 adult Rohingya refugees in Malaysia (response rate: 83\%), we examine whether a brief screening instrument of functional impairment, the WHO Disability Assessment Schedule (WHODAS), prove useful as a proxy measure to identify refugees who typically attend community mental health services. Based on estimates of mental disorder requiring interventions from analyses of epidemiological studies conducted worldwide, we selected a WHODAS cutoff that identified the top one-fifth of refugees according to severity of functional impairment, the remainder being distributed to moderate and lower impairment groupings, respectively. Compared to the lower impairment grouping, the severe impairment category comprised more boat arrivals (AOR: 5.96 [95\% Cl 1.34-26.43); stateless persons (A20.11 [95\% Cl 7.14-10); those with high exposure to pre-migration traumas (AOR: 4.76 [95\% Cl 1.64-13.73), peri-migration stressors (AOR: 1.26 [95\% Cl 1.14-1.39]) and postmigration living difficulties (AOR: 1.43 [95\% Cl 1.32-1.55); persons with single (AOR: 7.48 [95\% Cl 4.25-13.17]) and comorbid (AOR: 13.54 [95\% Cl 6.22-29.45]) common mental disorders; and those reporting poorer general health (AOR: 2.23 [95\% Cl 1-5.02]). In addition, half of the severe impairment grouping (50.6\%) expressed suicidal ideas compared to one in six (16.2 percent) of the lower impairment grouping (OR: 2.39 [95\% Cl 1.94-2.93]). Differences between the severe and moderate impairment groups were similar but less extreme. In settings where large-scale epidemiological studies are not feasible, the WHODAS may serve as readily administered and brief public health screening tool that assists in stratifying the population according to urgency of mental health needs.
\end{abstract}

\section{Introduction}

Recent United Nations reports have documented the extensive human rights violations committed over several

\footnotetext{
Correspondence: Alvin Kuowei Tay (alvin.tay@unsw.edu.au)

${ }^{1}$ Faculty of Medicine, School of Psychiatry, University of New South Wales, Sydney, NSW 2052, Australia

${ }^{2}$ Department of Psychology, Jagannath University, Dhaka, Bangladesh

Full list of author information is available at the end of the article
}

decades against the Rohingya minority of Myanmar ${ }^{1,2}$. Repeated episodes of violence and persecution committed by the Burmese military have forced successive waves of Rohingya-in total over 1.1 million since the 1980s-to flee their homeland in Rakhine state to surrounding Southeast Asian countries where they now constitute the largest population of refugees in the region (see Supplementary File 1 for the history of persecution of this group $)^{1}$. 
Identifying refugees in most urgent need of mental health and psychosocial (MHPSS) assistance presents a major challenge for planners and service providers when dealing with such large populations of displaced persons. In the present study, based on a large sample of Rohingya relocated to Malaysia, we examine whether a brief screening measure of functional impairment, the WHODAS, can identify refugees in greatest need of MHPSS services. Based on global estimates derived from two reviews of the literature ${ }^{3,4}$, between 10 and $15 \%$ of refugee populations require assistance for mental health problems. For the purposes of illustrating the potential use of the WHODAS as a screening measure, we therefore identify those in the highest $20 \%$ in the expectation that in real life health systems, only a half of these (that is, $10 \%$ of the total population) will seek or have access to services.

Existing methods for identifying mental health needs amongst large refugee populations tend to be limited in their utility because of their lack of specificity in identifying persons in urgent need of MHPSS care. Screening questionnaires based on mental health symptoms applied to refugees suggest that one in three refugees require attention, a task that far exceeds the capacity of existing services, for example, those available to the Rohingya in various sites in Southeast Asia $^{3}$. As indicated, in many situations of refugee concentration, there is a dearth of studies indicating population-wide MHPSS needs. One extant study based on a small sample of Rohingya refugees $(n=140)$ living in the humanitarian camps in Bangladesh found high rates of depression (89\%) and posttraumatic stress disorder (PTSD) (36\%), figures that provide little guidance in identifying those in most urgent need of intervention.

A further consideration is that refugees attending mental health services typically report experiencing a combination of CMDs (often in comorbid form) and a range of past and ongoing psychosocial stressors, including pre-migration traumatic events (TEs), perimigration stressors experienced during flight from the home country, and post-migration living difficulties (PMLDs) ${ }^{5,6}$. Assessing the full range of these experiences requires detailed and sensitive interviewing. Many also report physical health problems, adding to the complexity of assessments ${ }^{7}$. If a measure of functional impairment can provide a proxy index identifying refugees who exhibit this complex combination of problems, this would greatly aid the process of ensuring that scarce mental health services are used most efficiently in addressing those in greatest need of assistance.

In the present study, we examine the novel application of a brief measure of functional impairment, the WHODAS, to assess whether it may serve as a proxy indicator of the range of MHPSS problems commonly manifested by refugees attending mental health services. In past studies in the field, measures of functional impairment have been used to indicate the practical outcomes of MHPSS problems $^{8,9}$. Here we reverse the role by testing the use of the WHODAS as a possible proxy indicator of underlying MHPSS problems. We chose the WHODAS because it is a brief and widely applied measure of functional impairment with extant studies demonstrating ${ }^{8,10-12}$ sound psychometric properties.

Specifically, we examine whether stratification according to the WHODAS of refugees participating in a representative epidemiological study corresponds with a hierarchy of severity of MHPSS problems typical of patients attending mental health services. We predict that refugees assigned to the top $10 \%$ of scores on the WHODAS will report the highest prevalence of single and comorbid CMDs and physical ill-health as well as the most extreme exposure to pre-migration traumatic events and peri- and postmigration stressors.

\section{Materials \\ Subjects and methods \\ Base population and sampling}

According to estimates by community leaders, nongovernment organizations, and the UNHCR in Malaysia, $75 \%$ of the Rohingya community reside in and around the two major cities of Kuala Lumpur in Selangor state and Ipoh in Perak state. As a distinct group, the community lives in dense clusters in these geographical localities. Applying a cluster, probability proportional-to-size sampling framework, we identified 18 villages in Selangor and 31 in Perak (see Supplementary File 1 for full details). The survey team commenced at a fixed point and then identified all consecutive households along the street from one end to the other. We mapped and recorded all eligible persons in each dwelling. Eligible persons were selfidentified Rohingya originating from Myanmar or the offspring of at least one Rohingya parent. Based on our power analyses ( $90 \%$ power; alpha $=0.05$, two-sided test), our minimum sample size was 600 persons (approximately 300 in each of the two states). Of the 1156 adults approached, 197 (17\%) declined interview (all because of time commitments given their work schedules) the remainder consented to be interviewed, yielding a response rate of $83 \%$.

Ethical permission for the study was provided by the University of New South Wales Human Research Ethics Committee, Australia; and Perdana University-Royal College of Surgeons in Ireland School of Medicine, Malaysia, Institutional Review Board.

\section{Survey instruments}

We used the Refugee Mental Health Assessment Package (R-MHAP) ${ }^{13}$ to assess trauma events (TEs), perimigration stressors, postmigration living difficulties (PMLDs) and four common mental disorders (CMDs) 
relevant to the refugee experience (listed hereunder). Fuller details are provided in Supplementary File 2.

\section{Mental health indices}

We assessed current diagnoses of four CMDs known to be common amongst refugees, that is, posttraumatic stress disorder (PTSD), major depressive disorder (MDD), generalized anxiety disorder (GAD) and persistent complex bereavement disorder (PCBD) ${ }^{13}$ based on the Diagnostic and Statistical Manual, 5th edition (DSM5). Given that interviews were conducted by trained nonprofessional field workers, we refer to diagnoses as "probable". Suicidal ideation was assessed using an item on the depression screen: "how often have you thought about taking your own life in the last two weeks?". Persons identified as a suicide risk (who responded "yes") were referred to UNHCR affiliated health partners in Malaysia for a comprehensive assessment and where necessary, treatment.

We used the widely applied 12-item Short Form Health Survey (SF-12) to assess reports of general physical illhealth ${ }^{14}$. The item has yielded high levels of reliability and validity in comparison to more extensive assessments of physical health in past studies ${ }^{14}$.

The WHO Disability Assessment Schedule-Short Form (WHODAS 2.0) ${ }^{15}$ has been widely used in epidemiological surveys worldwide, yielding sound psychometric properties across cultures and contexts. The WHODAS was translated into the Rohingya language and adapted to the culture of Rohingya refugees living in Malaysia. For indicative purposes, we categorized persons into three impairment groups, that is, high (approximately top twenty percent), moderate (next one fifth), and lower (bottom three fifths). The closest rounded score on the WHODAS was 32 which identified 166 persons (17.3\% of the sample) who then formed the indicative high impairment group; the moderate impairment group (WHODAS score of 19-31 inclusive) included 220 persons (22.9\%); and the lower impairment group (WHODAS score 0-18) comprised 573 persons (59.8\%).

\section{Psychosocial adversity}

Lifetime exposure to pre-migration traumatic events (TEs) was measured by the R-MHAP module adapted to the context and history of the Rohingya. Items included exposure to war, torture, persecution, rape, murders, physical injuries, imprisonment, witnessing atrocities, and witnessing deaths of family members. The TE count ranged from 0 to 12 . To ensure roughly proportional representation in each category based on an examination of the distribution of scores, we derived three ordinal categories $(0-10,11-20,20$ counts or more).

Peri-migration stressors included extortion by people smugglers, starvation, physical assault, sexual abuse, and witnessing deaths or suicide of others. We applied the same binary response scale (exposed or not) as for the TE count. Peri-migration stressors (range 0-13) were ordered according to three ordinal categories: $0-5,6-10,11$ counts or more.

An adapted inventory of post-migration living difficulties (PMLDs) ${ }^{16}$ was used to assess common stressors confronted by the Rohingya communities in Malaysia. We used binary categories $(0=$ not a problem or a bit of a problem; $1=$ a moderately or a very serious problem), generating a total PMLD count (range 1-25). We derived three ordinal categories: $0-10,11-20,20$ counts or more.

All survey measures were translated into the Rohingya language. Interviews were conducted verbally in Ruáingga by field workers employed from the local Rohingya communities and responses were recorded on electronic tablet devices. The field team completed two weeks of training covering, inter alia, basic interviewing techniques (e.g. paraphrasing, clarifying, emphatic listening), refugee mental health, cultural sensitivity, research ethics, and risk assessment and management. The interviews took on average $45-60 \mathrm{~min}$.

\section{Statistical analysis}

We calculated sample size on expected odds ratios of major predictors of functional impairment (3.4 or greater). After generating frequencies and prevalence data for all variables, we conducted bivariate analyses to examine associations of explanatory variables with our three-tier functional impairment typology. Explanatory variables included social and demographic characteristics, length of residency in Malaysia, residency status, premigration TEs, peri-migration stressors (including travel mode), PMLDs, CMD status (one disorder, or two or more disorders), severity of suicidal ideation, and selfrated physical health (poor/fair vs good/excellent health) (see Supplementary File 2).

Multinomial logistic regression analysis was then used to characterize refugees assigned to the three functional groups, excluding variables (education and length of residency) which were not significant in bivariate analyses. Collinearity (VIF $>3.3$ ) amongst variables required that we conducted three separate regression models: Regression 1. Demographic and migration variables (age, gender, marital status, residency status, travel mode); Regression 2. Trauma and stressor variables: TEs, peri-migration stressors and PMLDs; Regression 3. CMD status and physical health. Suicidality was examined as a separate analysis given that the index formed part of the measure of major depression. We report odds ratios (ORs) and adjusted odds ratios (AORs) with 95\% confidence intervals (CIs) in each instance. Missing data were excluded from the analyses (see Supplementary File 2 for details). 


\section{Results}

Table 1 reports the sociodemographic characteristics of the analytic sample of 959 adults with a mean age of 28,3 years $(\mathrm{sd}=9,03)$, comprising 743 men $(77.5 \%)$. Refugees had resided for an average 47 months ( 4 four years) in Malaysia. The majority had arrived in Malaysia by boat $(n=835,87.1 \%)$ and received humanitarian protection status by UNHCR Malaysia $(n=687,71.6 \%)$. A quarter had completed primary school $(n=261,27.2 \%)$ and over a half were employed $(n=632,65.9 \%)$. Close to half of all adults were married ( $n=466,48.6 \%)$.

Descriptive data for TEs, peri-migration stressors, and PMLDs for the sample as a whole are reported in Supplementary File 2). In relation to TEs, the most widely endorsed items were torture $(n=775,81 \%)$, witnessing rape and other forms of sexual violence $(n=771,80 \%)$, shortage of food and water $(n=660,69 \%)$, and witnessing murders of friends and family members $(n=611,64 \%)$. In relation to peri-migration stressors, the majority of respondents reported being confined in overcrowded spaces with others for weeks $(n=923,96.2 \%)$, experiencing financial extortion by people smugglers $(n=915$, $95.4 \%)$, hiding to escape police or other authorities $(n=$ $872,90.9 \%$ ), and shortage of food and water during long journeys $(n=828,86.3 \%)$. The PMLDs identified as either a serious or a very serious problem included: poverty $(n=$ 864, 90.1\%); lack of aid from NGOs $(n=932,97.2 \%)$; poor access to healthcare $(n=788,82.2 \%)$; and inadequate shelter $(n=747,77.9 \%)$.

Table 2 reports the prevalence of the four probable CMD diagnoses. One third (306, 32\%) met criteria for PTSD, 115 (12\%) for MDD, 83 (9\%) for GAD, and 70 (7\%) for PCBD. Of those with a CMD, a third $(329,34.3 \%)$ had a single disorder, and $617(64.3 \%)$ had two or more disorders. Almost a quarter $(265,27.7 \%)$ rated their current physical health as fair or poor. Table 3 reports the distributions of key variables by severity of functional impairment.

\section{Bivariate analyses}

Table 4 reports bivariate analyses comparing severe versus lower functional impairment; moderate versus lower impairment; and severe versus moderate impairment categories respectively. For brevity, we report here only differences between the severe and lower impairment categories, the criterion used for inclusion of variables in subsequent multinomial regression analyses. Compared with the lower impairment category, more members of the severe impairment category were young, male, single, employed, boat arrivals, and stateless persons. In addition, the severe impairment group reported greater exposure to TEs (21 counts or more), peri-migration stressors (11 counts or more), and PMLDs (11-20, 21 counts or more). The severe impairment group also reported higher rates
Table 1 Social and demographic characteristics of the sample $(\boldsymbol{n}=959)$

\begin{tabular}{|c|c|c|}
\hline Sociodemographic variables & $N$ & $\% / s d$ \\
\hline \multicolumn{3}{|l|}{ Age } \\
\hline $18-30$ & 644 & $67.2 \%$ \\
\hline $31-40$ & 175 & $18.2 \%$ \\
\hline 41 and above & 140 & $14.6 \%$ \\
\hline Mean age (in years) & 28.3 & 9.03 \\
\hline average length of time (in months) in Malaysia & 47 & 43.68 \\
\hline \multicolumn{3}{|l|}{ Gender $^{\mathrm{ag}}$} \\
\hline Female & 171 & $17.8 \%$ \\
\hline Male & 743 & $77.5 \%$ \\
\hline Total/combined & 914 & $95.3 \%$ \\
\hline \multicolumn{3}{|l|}{ Employment $^{\text {bg }}$} \\
\hline Unemployed & 120 & $12.5 \%$ \\
\hline Employed/domestic duties & 632 & $65.9 \%$ \\
\hline Total/combined & 752 & $78.4 \%$ \\
\hline \multicolumn{3}{|l|}{ Educational attainment ${ }^{c \mathrm{~g}}$} \\
\hline Illiterate/no education & 538 & $56.1 \%$ \\
\hline Completed primary education & 261 & $27.2 \%$ \\
\hline Total/combined & 799 & $83.3 \%$ \\
\hline \multicolumn{3}{|l|}{ Marital status $^{\mathrm{dg}}$} \\
\hline Single/unmarried & 360 & $37.5 \%$ \\
\hline Married/widowed & 466 & $48.6 \%$ \\
\hline Total/combined & 826 & $86.1 \%$ \\
\hline \multicolumn{3}{|l|}{ Residency status ${ }^{\mathrm{eg}}$} \\
\hline UNHCR protection status & 687 & $71.6 \%$ \\
\hline Stateless & 183 & $19.1 \%$ \\
\hline Total/combined & 870 & $90.7 \%$ \\
\hline \multicolumn{3}{|l|}{ Mode of travel to Malaysia ${ }^{\mathrm{fg}}$} \\
\hline By boat & 835 & $87.1 \%$ \\
\hline By car or other means & 73 & $7.6 \%$ \\
\hline Total/combined Total/combined & 908 & $94.7 \%$ \\
\hline
\end{tabular}

${ }^{\mathrm{a}} 41$ missing

b207 missing

c160 missing

d 133 missing

e 89 missing

$\mathrm{f}_{51}$ missing

${ }^{9}$ missing data

of single and multiple CMDs; and of poor general health $\left(P<0.05\right.$ for all $X^{2}$ tests $)$.

\section{Multinomial logistic regression analyses}

Table 5 reports the findings of the multivariate analyses. 
Table 2 Estimate prevalence of comorbid mental disorders based on DSM-5 criteria with severe functional impairment in a community sample of Rohingya refugees living in Malaysia $(n=959)$

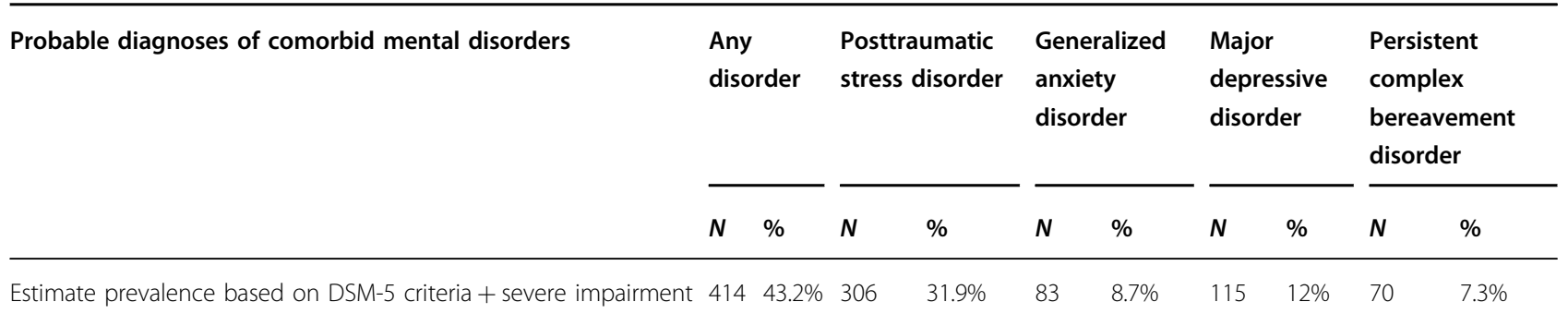

Operational criteria for deriving probable diagnoses using severe rating for functional impairment on the R-MHAP for PTSD, GAD, MDD, and PCBD. In addition, we specified additional criteria for PTSD in which symptom duration must exceed 3 months; for PCBD, symptoms must be experienced every day since onset of loss in the last 12 months with severe impairment

\section{Severe versus lower impairment categories}

Compared with the lower impairment category, the severe impairment category comprised more boat arrivals (AOR: 5.96 [95\% CI 1.34-26.43) and stateless persons (AOR: 20.11 [95\% CI 7.14-10). The severe impairment category also reported higher rates of pre-migration TEs (AOR: 4.76 [95\% CI 1.64-13.73), peri-migration stressors (AOR: 1.26 [95\% CI 1.14-1.39]) and PMLDs (AOR: 1.43 [95\% CI 1.32-1.55). The severe impairment group reported higher rates of single (AOR: 7.48 [95\% CI 4.25-13.17]) and in particular, comorbid (AOR: 13.54 [95\% CI 6.22-29.45]) CMDs, as well as poorer general health (AOR: 2.23 [95\% CI 1-5.02]).

\section{Moderate versus lower impairment categories}

Compared with the lower impairment group, more members of moderate impairment category were stateless (AOR: 1.75 [95\% CI 1.06-2.94). They also experienced greater exposure to both pre-migration TEs (AOR: 3.19 [95\% CI 1.22-8.34]) and PMLDs (AOR: 1.1 [95\% CI 1.04-1.15]); and had a higher prevalence of single (AOR: 1.65 [95\% CI 1.04-2.61]) and comorbid (AOR: 4.03 [95\% CI 1.97-8.27]) CMDs. There was no difference between the moderate and lower impairment groups in physical health status.

\section{Severe versus moderate impairment categories}

Compared with the moderate impairment category, the severe impairment category comprised more men (AOR: 2.51 [95\% CI 1-6.28]), persons who were employed (AOR: 3.99 [95\% CI 1.63-9.76]) and those who were stateless (AOR: 10 [95\% CI 2.86-3.33]). The severe impairment category also reported higher rates of both peri-migration stressors (AOR: 1.16 [95\% CI 1.04-1.30]) and PMLDs (AOR: 1.37 [95\% CI 1.24-1.51]). They recorded more single (AOR: 4.30 [95\% CI 2.21-8.35]) and comorbid (AOR: 3.19 [95\% CI 1.49-6.81]) CMDs. There was no difference in TEs and physical health status between the two impairment groups.
There was a clear gradient in relation to the item assessing severity of suicidal ideation. Half $(50.6 \%)$ of those in the severe impairment group, a quarter $(23.2 \%)$ in the moderate and approximately one in eight (16.2\%) of those in the lower impairment groups reported high levels of suicidal ideation $(\mathrm{H}(2)=73.66, p<=.001)$. The univariate odds ratio comparing the high impairment versus the lower impairment groups on this item was 2.39 [95\% CI 1.94-2.93].

In summary, there was a clear gradient on virtually all relevant indices across the three functional impairment groupings. For example, for CMDs, persons with one or more disorders comprised one third $(176,31 \%)$ of the lower impairment group, a half $(116,53 \%)$ of the moderate impairment group, and three fourths $(122,74 \%)$ of the severe impairment group. The only index that did not conform to this pattern was that of physical ill-health (across all three groups, reporting of physical ill-health ranged from $71-77 \%$ ).

As an indication of the convergence of psychosocial, mental and physical problems, those recording both a CMD and fair/poor physical health $(580,60 \%)$ reported significantly greater exposure to TEs $(m=12.9, \mathrm{sd}=7.04$ vs $\mathrm{m}=9.93$, $\mathrm{sd}=6.08 ; \mathrm{t}(902)=-6.96, p<0.001)$, perimigration stressors $(\mathrm{m}=8.26, \quad \mathrm{sd}=3.22 \mathrm{~m}=7.1, \quad \mathrm{sd}=$ 3.45; $\mathrm{t}(790)=-5.27, p<0.001)$ and PMLDs $(m=14.44$, $\mathrm{sd}=5.15 \mathrm{~m}=12.18, \mathrm{sd}=5.48 ; \mathrm{t}(793)=-6.41 ; p<0.001)$.

\section{Discussion}

Our study revealed high levels of exposure to TEs, perimigration stressors and PMLDs, amongst Rohingya refugees in general. Those stratified to the top twenty percent of functional impairment on the WHODAS reported high levels of exposure to all domains of psychosocial stressors as well as a high prevalence of CMDs, particularly the comorbid pattern. Importantly, one in two refugees in the high functional impairment group reported suicidal ideation. Overall, these findings suggest that the WHODAS may be effective as a screen used to 
Table 3 Distributions of sociodemographic variables, pre-migration, peri-migration, post-migration $\infty$ traumarelated and psychosocial risk factors, mental disorders, and physical impairment by severity of functional impairment $(n=959) \pm$

\begin{tabular}{lllll}
\hline Sociodemographic variables & $\begin{array}{l}\text { Low } \\
(n=573)\end{array}$ & $\begin{array}{l}\text { Moderate } \\
(n=220)\end{array}$ & $\begin{array}{l}\text { Severe } \\
(n=166)\end{array}$
\end{tabular}$\quad$ X2 tests

\begin{tabular}{|c|c|c|c|c|c|c|c|}
\hline \multicolumn{8}{|l|}{ Age } \\
\hline $18-30$ & 370 & 64.6 & 148 & 67.3 & 126 & 75.9 & \\
\hline $31-40$ & 104 & 18.2 & 42 & 19.1 & 29 & 17.5 & \\
\hline 41 and above & 99 & 17.3 & 30 & 13.6 & 11 & 6.6 & $P=0.021$ \\
\hline \multicolumn{8}{|l|}{$G^{-}{ }^{a} d e{ }^{a}$} \\
\hline Female & 136 & 25.6 & 26 & 11.9 & 9 & 5.3 & \\
\hline Male & 395 & 74.4 & 192 & 88.1 & 156 & 94 & $P<.001$ \\
\hline \multicolumn{8}{|l|}{ Employment ${ }^{\mathrm{a}}$} \\
\hline Unemployed & 78 & 17.8 & 34 & 21 & 8 & 5.3 & \\
\hline Employed/domestic duties & 360 & 82.2 & 128 & 79 & 144 & 86.7 & $P<0.001$ \\
\hline \multicolumn{8}{|l|}{ Educational attainment ${ }^{\mathrm{a}}$} \\
\hline Illiterate/no education & 307 & 66.2 & 134 & 69.4 & 97 & 68.3 & \\
\hline Completed primary education & 157 & 33.8 & 59 & 30.6 & 45 & 31.7 & $P=0.692$ \\
\hline \multicolumn{8}{|l|}{ Marital status ${ }^{a}$} \\
\hline Single/unmarried & 184 & 38.7 & 90 & $46 \cdot 6$ & 86 & $54 \cdot 4$ & \\
\hline Married/widowed & 291 & 61.3 & 103 & 53.4 & 72 & 45.6 & $P<0.001$ \\
\hline \multicolumn{8}{|l|}{ Residency status $^{\mathrm{a}}$} \\
\hline Held UNHCR refugee status ${ }^{b}$ & 382 & 72.8 & 174 & 82.5 & 131 & 97.8 & \\
\hline $\begin{array}{l}\text { Stateless (without UNCHR } \\
\text { protection) }^{\mathrm{c}}\end{array}$ & 143 & 27.2 & 37 & 17.5 & 3 & 2.2 & $P<0.001$ \\
\hline \multicolumn{8}{|l|}{ Exposure to pre-migration TEs } \\
\hline $0-10$ counts & 273 & $47 \cdot 6$ & 70 & $31 \cdot 8$ & 67 & 40.4 & \\
\hline $11-20$ counts & 264 & 46.1 & 124 & 56.4 & 61 & 36.8 & \\
\hline 21 counts or more & 36 & 6.3 & 26 & 11.8 & 38 & 22.9 & $P<0.001$ \\
\hline \multicolumn{8}{|l|}{ Exposure to peri-migration stressors } \\
\hline $0-5$ counts & 157 & 27.4 & 34 & 15.5 & 11 & 6.6 & \\
\hline $6-10$ counts & 333 & 58.1 & 133 & 60.5 & 77 & 46.4 & \\
\hline 11 counts or more & 83 & 14.5 & 53 & 24.1 & 78 & 47 & $P<0.001$ \\
\hline \multicolumn{8}{|l|}{ Mode of travel to Malaysia ${ }^{a}$} \\
\hline By boat & 469 & 89.2 & 203 & 93.6 & 163 & 98.8 & \\
\hline By car or other means & 57 & 10.8 & 14 & 6.5 & 2 & 1.2 & $P<0.001$ \\
\hline \multicolumn{8}{|l|}{ Post-migration living difficulties ${ }^{d}$} \\
\hline $0-10$ counts & 206 & 37.3 & 36 & 16.7 & 5 & 3.1 & \\
\hline $11-20$ counts & 302 & 54.7 & 165 & 76.7 & 122 & 74.4 & \\
\hline 21 counts or more & 44 & 8 & 14 & 6.5 & 37 & 22.6 & $P<0.001$ \\
\hline \multicolumn{8}{|l|}{ Overall self-rated physical health } \\
\hline Excellent/very good & 168 & 70.6 & 59 & 26.8 & 38 & 22.9 & \\
\hline Fair/poor & 404 & 29.4 & 161 & 73.2 & 128 & 77.1 & $P<0.001$ \\
\hline \multicolumn{8}{|l|}{ Mental disorders } \\
\hline No disorder & 397 & 69.3 & 104 & 47.3 & 44 & 26.5 & \\
\hline One disorder & 138 & 24.1 & 76 & 34.6 & 82 & 49.4 & \\
\hline Two or more disorders & 38 & 6.6 & 40 & 18.2 & 40 & 24.1 & $P<0.001$ \\
\hline
\end{tabular}

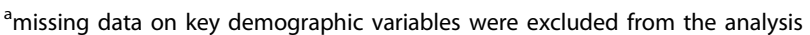
${ }^{b}$ Participants were recognized as genuine refugees by UNHCR following Refugee Status Determination (RSD)

'Participants did not hold UNHCR protection status at the time of the survey

${ }^{\mathrm{d}}$ Post-migration living difficulties were endorsed at moderate or severe levels

identify refugees in greatest need of psychosocial and mental health services ${ }^{17,18}$.

The study strengths include the probabilistic approach to sampling, the large sample size and the high response rate
(83\%). Restriction of the sample to one country and ethnic grouping limits the generalizability of our findings regarding the general utility of the WHODAS as a screening measure for refugees. Further studies in other refugee settings are needed to test the universal applicability of our findings. In each setting, the WHODAS will need to be culturally and linguistically adapted and field tested in order to re-calibrate the cut-off points. In general, although we followed a rigorous method for adapting and testing measures, the risk of transcultural error in measurement remains. Retrospective bias in recall of trauma events and peri-traumatic stressors may introduce inaccuracies in reporting. We note, however, that the traumas and stressors reported are consistent with the known history of Rohingya refugees displaced throughout Southeast Asia $^{19}$. Although we restricted the analysis to four CMDs, these diagnoses reflect the most general forms of mental disorder identified amongst refugees. We note that, contrary to our predictions, variations in reported physical illhealth showed little relationship to WHODAS stratification. It is possible that the measure used was too sensitive, failing to discriminate between severe and more moderate levels of physical ill-health. More detailed measures of physical ill-health, ideally corroborated by objective evidence, may improve the specificity of this index. Finally, our specification of a $20 \%$ threshold on the WHODAS was somewhat arbitrary and hence should be regarded as indicative only. We selected that threshold on the assumption that approximately half of the persons identified would ultimately seek and receive treatment, representing an attendance rate of $10 \%$ of the total refugee population (at a country level, approximately 5,000 persons of Rohingya background, excluding children and adolescents). Even that number of presentations to clinics would represent a major challenge in a setting such as Malaysia where there is a severe shortage of agencies specifically providing for the mental health of refugees. At the same time, it is likely that our estimates of those who would seek MHPSS services may be inflated given the cultural and practical barriers to seeking MHPSS assistance amongst the Rohingya. Factors that could inhibit seeking help include shame, social stigma, language issues, and concerns about confidentiality and impact of being seen to be mentally ill on rights to residency ${ }^{1}$.

Notwithstanding these limitations, our findings are of interest for several reasons. They offer the first systematic record of the extensive TEs, peri-migration stressors and PMLDs experienced by displaced Rohingya, the largest population of refugees currently dispersed across Southeast $\mathrm{Asia}^{20,21}$. Of particular note are the high rates of torture, imprisonment, and exposure to atrocities and murders reported by the sample. Further, the data reveal the extreme conditions that Rohingya experienced while traveling by boat to Malaysia, including extortion, 
Table 4 Univariate multinomial logistic regressions examining associations of sociodemographic, trauma-related, psychosocial, mental and physical predictors of severity of functional impairment in a community sample of Rohingya refugees living in Malaysia $(\boldsymbol{n}=959)$

\begin{tabular}{|c|c|c|c|c|c|c|}
\hline \multirow{2}{*}{$\begin{array}{l}\text { Reference group: low impairment }(n=573) \\
\text { Sociodemographic characteristics }\end{array}$} & \multicolumn{3}{|c|}{ Moderate impairment $(n=220)$} & \multicolumn{3}{|c|}{ Severe impairment $(n=166)$} \\
\hline & Odds Ratios & $\begin{array}{l}\text { 95\% Confidence } \\
\text { Interval }\end{array}$ & $P$ & Odds Ratios & $\begin{array}{l}95 \% \text { Confidence } \\
\text { Interval }\end{array}$ & $P$ \\
\hline $\begin{array}{l}\text { Age } \\
\text { Base cat: } 18-30 \text { years }\end{array}$ & 0.85 & $0.73-0.98$ & 0.029 & 0.70 & $0.58-0.86$ & $<0.001$ \\
\hline $\begin{array}{l}\text { Male sex } \\
\text { Base cat: female }\end{array}$ & 2.54 & $1.62-4$ & $<0.001$ & 5.97 & $2.96-12$ & $<0.001$ \\
\hline $\begin{array}{l}\text { Being employed } \\
\text { Base cat: unemployed }\end{array}$ & 0.97 & $0.61-1.54$ & 0.90 & 5.15 & $2.41-10.96$ & $<0.001$ \\
\hline $\begin{array}{l}\text { Completed primary or secondary education } \\
\text { Base cat: illiterate/no education }\end{array}$ & 0.84 & $0.61-1.17$ & 0.299 & 0.89 & $0.63-1.28$ & 0.544 \\
\hline $\begin{array}{l}\text { Being married } \\
\text { Base cat: single }\end{array}$ & 0.86 & $0.66-1.13$ & 0.28 & 0.64 & $0.47-0.86$ & 0.004 \\
\hline $\begin{array}{l}\text { Residency status (being stateless) } \\
\text { Base cat: UNHCR protection status }\end{array}$ & 1.75 & $1.18-2.63$ & 0.006 & $16 \cdot 67$ & $5-50$ & $<0.001$ \\
\hline $\begin{array}{l}\text { Exposure to pre-migration Traumatic Events (TEs) } \\
\text { (mean score) }\end{array}$ & 3.27 & $1 \cdot 70-6 \cdot 29$ & $<0.001$ & 3.4 & $1.66-7.03$ & $<0.001$ \\
\hline Peri-migration stressors (base cat: 0 count) & 1.11 & $1.05-1.16$ & $<0.001$ & $1 \cdot 38$ & $1.27-1.49$ & $<0.001$ \\
\hline $\begin{array}{l}\text { Traveled to Malaysia by boat } \\
\text { Base cat: traveled by land transport } \\
\text { Post-migration living difficulties (PMLDs) }\end{array}$ & 1.76 & $0.96-3.23$ & 0.067 & 9.90 & $2.39-41$ & 0.002 \\
\hline $\begin{array}{l}\text { Exposure to post-migration living difficulties endorsed at } \\
\text { moderate and severe levels (mean score) }\end{array}$ & 1.08 & $1.05-1.12$ & $<0.001$ & $1 \cdot 25$ & $1.20-1.3$ & $<0.001$ \\
\hline $\begin{array}{l}\text { Overall self-rated physical health (base cat: very good/ } \\
\text { excellent) }\end{array}$ & & & & & & \\
\hline Poor/fair & 2.16 & $1 \cdot 17-3.98$ & 0.337 & 2.16 & $1.17-3.98$ & 0.013 \\
\hline Mental disorders (base cat: no disorder) & & & & & & \\
\hline One disorder & 2.1 & $1.48-2.99$ & $<0.001$ & 4.02 & $2.45-6.58$ & $<0.001$ \\
\hline Two or more disorders & 5.36 & $3.54-8.11$ & $<0.001$ & 9.50 & $5 \cdot .52-16.34$ & $<0.001$ \\
\hline
\end{tabular}

extreme deprivations, and physical threats. In that respect, our study confirms other accounts of human rights agencies and UN missions detailing the extensive exposure to persecution and social duress experienced by the Rohingya population in general ${ }^{22,23}$. Traveling to Malaysia by boat (rather than over land) is an indicator of the urgency of the need to flee given the dangers involved in embarking on sea voyages in unsafe craft. In Malaysia, Rohingya refugees continue to experience severe challenges relating to inadequate housing, access to education and health, poverty, and in obtaining legal support. Our findings also detail the extent of the mental health problems experienced by these refugees, including the high prevalence of comorbid patterns of CMDs.
A key aim of the study was to assess whether a brief measure of functional impairment was able to identify a subpopulation of refugees exhibiting the psychosocial and psychiatric characteristics of persons who typically attend mental health services when they are available. The indicative approach of stratifying refugees into the top twenty percent stratum of functional impairment according to the WHODAS defined a subpopulation characterized by high levels of exposure to psychosocial stressors and in whom there was a concentration of comorbid CMDs, especially compared to the lower impairment group. At the same time, a substantial number of persons experiencing CMDs fell into the moderate and even lower functional impairment categories. That observation suggests that the 
Table 5 Multivariate multinomial logistic regressions" examining associations of sociodemographic, trauma-related, psychosocial, mental and physical health predictors of functional impairment by levels of severity in a community sample of Rohingya refugees living in Malaysia $(n=959)$

\begin{tabular}{|c|c|c|c|c|c|c|}
\hline \multirow{2}{*}{$\begin{array}{l}\text { Reference group: low impairment }(n=573) \\
\text { Sociodemographic characteristics }\end{array}$} & \multicolumn{3}{|c|}{ Moderate impairment $(n=220)$} & \multicolumn{3}{|c|}{ Severe impairment $(n=166)$} \\
\hline & $\begin{array}{l}\text { Adjusted } \\
\text { odds ratios }\end{array}$ & $\begin{array}{l}95 \% \text { confidence } \\
\text { interval }\end{array}$ & $P$ & $\begin{array}{l}\text { Adjusted } \\
\text { odds ratios }\end{array}$ & $\begin{array}{l}95 \% \text { confidence } \\
\text { interval }\end{array}$ & $P$ \\
\hline $\begin{array}{l}\text { Age } \\
\text { Base cat: } 18-30 \text { years }\end{array}$ & 0.87 & $0.65-1.15$ & 0.319 & 1.03 & $0.73-1.44$ & 0.874 \\
\hline $\begin{array}{l}\text { Gender } \\
\text { Base cat: female }\end{array}$ & 2.27 & $0.82-6.28$ & 0.116 & 2.22 & $0.22-5.44$ & 0.982 \\
\hline $\begin{array}{l}\text { Being employed } \\
\text { Base cat: unemployed }\end{array}$ & 0.87 & $0.51-0.54$ & 0.90 & 4.15 & $1.41-8.96$ & $<0.001$ \\
\hline $\begin{array}{l}\text { Being married } \\
\text { Base cat: single }\end{array}$ & 1.17 & $0.79-1.73$ & 0.424 & 0.67 & $0.42-1.06$ & 0.085 \\
\hline $\begin{array}{l}\text { Residency status (being stateless) } \\
\text { Base cat: held UNHCR protection status }\end{array}$ & 1.75 & $1.06-2.94$ & 0.028 & 20.11 & $7.14-10$ & $<0.001$ \\
\hline $\begin{array}{l}\text { Exposure to pre-migration Traumatic Events (TEs) } \\
\text { (mean score) }\end{array}$ & 3.19 & $1.22-8.34$ & 0.018 & 4.76 & $1.64-13.73$ & 0.004 \\
\hline Peri-migration stressors (base cat: 0 count) ${ }^{\mathrm{a}}$ & 1.05 & $0.98-1.12$ & 0.188 & 1.26 & $1.14-1.39$ & $<0.001$ \\
\hline $\begin{array}{l}\text { Traveled to Malaysia by boat } \\
\text { Base cat: traveled by land transport }\end{array}$ & 1.23 & $0.59-2.53$ & 0.581 & 5.96 & $1.34-26.43$ & 0.019 \\
\hline \multicolumn{7}{|l|}{ Post-migration living difficulties (PMLDs) } \\
\hline $\begin{array}{l}\text { Exposure to post-migration living difficulties } \\
\text { endorsed at moderate and severe levels } \\
\text { (mean score) }\end{array}$ & 1.1 & $1.04-1.15$ & $<0.001$ & 1.43 & $1.32-1.55$ & $<0.001$ \\
\hline \multicolumn{7}{|l|}{$\begin{array}{l}\text { Overall self-rated physical health (base cat: very } \\
\text { good/excellent) }\end{array}$} \\
\hline Poor/fair & 1.90 & $0.91-3.96$ & 0.088 & 2.23 & $1-5.02$ & 0.05 \\
\hline \multicolumn{7}{|l|}{ Mental disorders (base cat: no disorder) ${ }^{a}$} \\
\hline One disorder & 1.65 & $1.04-2.61$ & 0.034 & 7.48 & $4.25-13.17$ & $<0.001$ \\
\hline Two or more disorders & 4.03 & $1.97-8.27$ & $<0.001$ & 13.54 & $6.22-29.45$ & $<0.001$ \\
\hline
\end{tabular}

${ }^{\mathrm{a} G i v e n ~ h i g h ~ m u l t i-c o l l i n e a r i t y ~ b e t w e e n ~ m e n t a l ~ d i s o r d e r s, ~ g e n e r a l ~ h e a l t h, ~ p r e-~ a n d ~ p e r-m i g r a t i o n ~ e x p o s u r e ~ a n d ~ P M L D s, ~ t h e s e ~ v a r i a b l e s ~ w e r e ~ e n t e r e d ~ i n t o ~ s e p a r a t e ~}$ multivariate logistic regressions; education was excluded because of high multi-collinearity

presence of CMD on its own does not necessarily imply high levels of functional impairment, that is, many refugees continue to function and cope in spite of experiencing substantial levels of symptoms, for example, of depression ${ }^{24}$. Ideally, however, even these persons should be provided with mental health care if they so choose. The finding of severe impairment being associated with employment may be attributable to the poor working conditions confronted by Rohingya refugees in Malaysia.

In summary, our findings offer preliminary evidence that a brief screening measure of functional impairment, the WHODAS may prove useful in identifying refugees in greatest need of MHPSS attention. The data indicate a close convergence between high scores on the WHODAS and a constellation of MHPSS characteristics typical of persons attending mental health services, that is, exhibiting a combination of CMDs (including comorbidity) and severe background psychosocial stressors extending from exposure to trauma in the home country through to severe adversity in the peri- and postmigration environment. The urgency of need is further illustrated by the finding that half of those in the high functional impairment group experienced high levels of suicidal ideation.
Further evaluations are needed to assess the utility of the WHODAS as a potential screening tool for MHPSS needs across a range of refugee groups from a range of cultures and backgrounds.

\section{Acknowledgements}

We thank all our field personnel for their invaluable contributions to this project. National Health and Medical Research Council (NHMCR) Program Grant; National Health and Medical Research Council (NHMCR) Early Career Fellowship.

\footnotetext{
Author details

${ }^{1}$ Faculty of Medicine, School of Psychiatry, University of New South Wales, Sydney, NSW 2052, Australia. ${ }^{2}$ Department of Psychology, Jagannath University, Dhaka, Bangladesh. ${ }^{3}$ School of Medicine, Perdana University-Royal College of Surgeons in Ireland (PU-RCSI), Selangor, Malaysia. ${ }^{4}$ Health Unit, United Nations High Commissioner for Refugees (UNHCR), Kuala Lumpur, Malaysia
}

Conflict of interest

The authors declare that they have no conflict of interest.

Publisher's note

Springer Nature remains neutral with regard to jurisdictional claims in published maps and institutional affiliations. 
Supplementary Information accompanies this paper at (https://doi.org/ 10.1038/s41398-019-0537-z).

Received: 28 November 2018 Revised: 15 May 2019 Accepted: 7 July 2019 Published online: 02 September 2019

\section{References}

1. Tay, A. K. et al. The culture, mental health and psychosocial wellbeing of Rohingya refugees: a systematic review. Epidemiolo. Psychiatr. Sci. 1-6, https:// doi.org/10.1017/S2045796019000192 (2019).

2. Darusman, M. Statement by Chairperson of the Independent International FactFinding Mission on Myanmar, at the 37th session of the Human Rights Council. (United Nations Human Rights Council Geneva, Switzerland, 2018).

3. Steel, Z. et al. Association of torture and other potentially traumatic events with mental health outcomes among populations exposed to mass conflict and displacement: A systematic review and meta-analysis. JAMA 302, 537-549 (2009).

4. Charlson, F. J. et al. Post-traumatic stress disorder and major depression in conflict-affected populations: an epidemiological model and predictor analysis. Glob. Ment. health (Camb., Engl.) 3, e4, https://doi.org/10.1017/ gmh.2015.26 (2016).

5. Tay, A. K., Rees, S., Chen, J., Kareth, M. \& Silove, D. Factorial structure of complicated grief: associations with loss-related traumatic events and psychosocial impacts of mass conflict amongst West Papuan refugees. Soc. psychiatry Psychiatr. Epidemiol. 51, 395-406, https://doi.org/10.1007/s00127015-1099-x (2016)

6. Momartin, S., Silove, D., Manicavasagar, V. \& Steel, Z. Complicated grief in Bosnian refugees: associations with posttraumatic stress disorder and depression. Comprehensive psychiatry 45, 475-482, https://doi.org/10.1016/j. comppsych.2004.07.013 (2004).

7. Van Ommeren, M. et al. The relationship between somatic and PTSD symptoms among Bhutanese refugee torture survivors: examination of comorbidity with anxiety and depression. J. Trauma. Stress.: Off. Publ. Int. Soc. Trauma. Stress. Stud. 15, 415-421 (2002).

8. Purgato, M. et al. Focused psychosocial interventions for children in lowresource humanitarian settings: a systematic review and individual participant data meta-analysis. Lancet Glob. health 6, e390-e400, https://doi.org/10.1016/ s2214-109x(18)30046-9 (2018).

9. Archambeau, O. G., Elhai, J. D. \& Frueh, B. C. Definition of psychological trauma and threshold for functional impairment in PTSD. J. Clin. Psychiatry 72, 416-417 (2011).
10. Bass, J. et al. A controlled trial of problem-solving counseling for war-affected adults in Aceh, Indonesia. Soc. Psychiatry Psychiatr. Epidemiol. 47, 279-291, https://doi.org/10.1007/s00127-011-0339-y (2012).

11. Rasmussen, A. et al. Rates and impact of trauma and current stressors among Darfuri refugees in Eastern Chad. Am. J. Orthopsychiatry 80, 227-236, https:// doi.org/10.1111/j.1939-0025.2010.01026x (2010).

12. Bolton, P. et al. A transdiagnostic community-based mental health treatment for comorbid disorders: development and outcomes of a randomized controlled trial among Burmese refugees in Thailand. PLoS Med. 11, e1001757, https://doi.org/10.1371/journal.pmed.1001757 (2014).

13. Tay, A. K. et al. The Refugee-Mental Health Assessment Package (R-MHAP); rationale, development and first-stage testing amongst West Papuan refugees. Int. J. Ment. Health Syst. 9, 29 (2015).

14. Gandek, B. et al. Cross-validation of item selection and scoring for the SF-12 Health Survey in nine countries: results from the IQOLA Project. International Quality of Life Assessment. J. Clin. Epidemiol. 51, 1171-1178 (1998).

15. Ustun, T. B. et al. Developing the World Health Organization disability assessment schedule 2.0. Bull. World Health Organ. 88, 815-823 (2010).

16. Semrau, M. et al. The development and psychometric properties of the Humanitarian Emergency Settings Perceived Needs (HESPER) Scale. Am. J. Public Health 102, e55-e63, https://doi.org/10.2105/ajph.2012.300720 (2012).

17. Zraly, M., Rubin-Smith, J. \& Betancourt, T. Primary mental health care for survivors of collective sexual violence in Rwanda. Glob. public health $\mathbf{6}$ 257-270, https://doi.org/10.1080/17441692.2010.493165 (2011).

18. Jones, L. et al. Severe mental disorders in complex emergencies. Lancet $\mathbf{3 7 4}$ 654-661 (2009).

19. Riley, A., Varner, A., Ventevogel, P., Taimur Hasan, M. M. \& Welton-Mitchell, C. Daily stressors, trauma exposure, and mental health among stateless Rohingya refugees in Bangladesh. Transcult. psychiatry 54, 304-331, https://doi.org/ 10.1177/1363461517705571 (2017).

20. Charney, M. W. The Rohingyas of Myanmar: an under-reported genocide? Political Q. 88, 541-543 (2017).

21. Reed, J. Rohingya exodus points to humanitarian crisis in Myanmar. FT.com https://www.ft.com/content/719a83b0-915e-11e7-bdfa-eda243196c2c (2017).

22. Brooten, L., Ashraf, S. I. \& Akinro, N. A. Traumatized victims and mutilated bodies: human rights and the 'politics of immediation'in the Rohingya crisis of Burma/Myanmar. Int. Commun. Gaz. 77, 717-734 (2015).

23. Mahmood, S. S., Wroe, E., Fuller, A. \& Leaning, J. The Rohingya people of Myanmar: health, human rights, and identity. Lancet (Lond., Engl.) 389, 1841-1850, https://doi.org/10.1016/s0140-6736(16)00646-2 (2017).

24. Friis Jorgensen, S., A Auning-Hansen, M., Edward Ottesen Kennair, L. \& Elklit, A. Can disability predict treatment outcome among traumatized refugees? Torture 27, 12-26 (2017).c 